\title{
STERN TUBE PERANNYA SEBAGAI MEDIA PELUMASAN DAN KEKEDAPAN POROS BALING-BALING KAPAL
}

\author{
Budi Utomo \\ Program Studi D3 Teknologi Perencanaan dan Konstuksi Kapal ,Departemen Teknologi Industri, \\ Sekolah Vokasi , Universitas Diponegoro Semarang \\ Jl. Prof. Soedarto, SH, Kampus Undip Tembalang, Semarang 50275 \\ Email:
}

\begin{abstract}
Abstrak
Poros baling-baling berputar didalam tabung sehingga perlu dilengkapi dengan sistim pelumasan. Ada dua macam sistim pelumasan poros baling-baling yaitu sistim pelumasan dengan air laut dan sistim pelumasan dengan minyak. Didalam tabung poros dibagian ujung depan dan ujung belakang dipasang bantalan poros, seal dan paking, hal ini bertujuan agar bekerjanya sistim pelumasan dan kekedapan poros baling-baling dapat bekerja dengan baik. Karena tabung poros digunakan sebagai media pelumasan dengan bahan pelumas yang berbeda, maka bahan bantalan, paking dan seal terbuat dari bahan yang berbeda sehinggamampu mendukung kinerja sistim pelumasan dan kekedapannya.Masingmasing komponen tersebut tidak dapat saling dipisahkan karena selalu erat berhubungan satu sama lain..
\end{abstract}

Kata Kunci : “Stern Tube”, “poros propeller”, “pelumasan dan kekedapan”.

\section{Pendahuluan}

Tabung poros atau tabung buritan adalah tabung yang terbuat dari besi tuang atau baja yang menyelubungi poros baling-baling yang dipasang diantara sekat kedap air buritan dan linggi baling-baling dan disebut juga sebagai tabung poros baling-baling. Seperti diketahui bahwa setiap benda yang berputar terhadap benda yang menimbulkan gesekan perlu padanya diberikan media pelumas, sebab tanpa ada pelumasan maka permukaan benda yang berputar itu akan langsung bergesekan yang mengakibatkan timbul panas dan akhirnya dengan cepat akan merusak permukaan masing-masing benda tersebut.Secara garis besar ada dua macam sistem pelumasan pada poros baling-baling terhadap bantalan, yaitupelumasan dengan air laut dan pelumasan dengan minyak.Dengan adanya dua macam sistem pelumasan itu, maka jenis bantalan yang digunakan pada masing-masing sistem juga berbeda, dimana pada sistem pelumasan dengan air laut tanpa menggunakan sistem kedap poros, sedangkan pada sistem pelumasan dengan minyak pelumas harus digunakan sistem kedap poros agar minyak pelumas tidak bercampur dengan air laut.
Pada instalasi sistem poros penggerak kapal yaitu hubungan antara mesin induk, poros baling-baling, bantalan poros dan sebagainya, tabung poros baling-baling adalah berupa suatu pipa yang mempunyai ketebalan tertentu yang dihubungkan pada badan kapal dengan pertolongan bos linggi baling-baling pada bagian belakang dan bagian depannya dipegang oleh sekat yang paling belakang

(sekat ceruk buritan) dan tingginya segaris dengan sumbu poros mesin penggerak dengan tujuan untuk mempertahankan kelurusan poros baling-baling dan menghindari goyangan poros yang berlebihan serta menahan gaya yang sangat besar dari sentakan poros baling-baling yang berputar didalam air.Didalam tabung poros dibagian ujung depan dan belakang dipasangkan bantalan poros, seal, paking dan perlengkapannya, hal ini bertujuan agar bekerjanya sistem pelumasan dan sistem kekedapan poros baling-baling dapat berjalan dengan baik. Pada pelaksanaan reparasi kapal , sering dijumpai bahwa posisi bantalan belakang, bantalan depan dan mesin induk tidak satu sumbu lagi antara yang satu dengan yang lainnya. Hal ini terjadi karena beberapa hal yaitu adanya deformasi 
pengelasan karena penggantian pelat badan kapal, pemasangan ganjel-ganjel pada waktu docking yang kurang tepat sehingga dapat mengubah kedudukan sumbu poros balingbaling, adanya keausan pada salah satu bagian stern tube terutama pada kedudukan rumah bantalan sehingga posisinya berubah atau karena hal lain yang tidak terduga sebelumnya.

\section{Dasar Teori}

Apabila terjadi gerakan relatif antara dua benda yang bersentuhan, terjadilah gesekan antara kedua benda itu. Gesekan (mekanik) tersebut terutama disebabkan oleh permukaan benda yang kasap tetapi mungkin juga oleh adhesi antara kedua permukaan atau oleh reaksi kimia yang terjadi pada permukaan itu. Gesekan yang terjadi pada motor bakar, misalnya antara poros dan bantalan, antara cincin torak dan dinding silinder, antara roda gigi dan sebagainya. Untuk mengatasi gesekan itu, agar benda yang bersentuhan bisa digerakkan ,maka diperlukan gaya. Karena itu besarnya gesekan harus dibatasi agar daya mesin tidak banyak yang hilang pada bantalan, roda gigi dan sebagainya. Selain itu gesekan dapat mengauskan permukaan, sedangkan kerusakan selanjutnya dipercepat oleh panas yang terjadi karena gesekan itu. Besarnya gesekan dapat dikurangi dengan menggunakan minyakpelumas yang fungsinya memisahkan dua permukaan yang bersentuhan. Akan tetapi di dalam kenyataannya tidak ada gerakan tanpa gesekan karena tidaklah mudah untuk memperoleh pemisahan yang sempurna. Lagi pula gesekan terjadi juga pada permukaan yang dilumasi itu yang disebabkan oleh adanya tegangan geser pada pelumasnya sendiri. Pada umumnya motor bakar torak menggunakan pelumas cair yang dinamai minyak pelumas. Selain mudah disalurkan minyak pelumas itu berfungsi juga sebagai fluida pendingin, pembersih dan penyekat. Minyak pelumas harus dapat mencapai seluruh bagian yang hendak dilumasi serta harus dapat memenuhi tugasnya dengan baik.( Wiranto Arismunandar, 1988 )

Daya efektif ( PE ) adalah besar daya yang dibutuhkan untuk mengatasi gaya hambat dari badan kapal ( hull ) agar kapal dapat bergerak dengan kecepatan servis sebesar Vs $\mathrm{P}=\mathrm{R} \times \mathrm{Vs}$. Daya dorong ( PT ) adalah besarnya daya yang dihasilkan oleh kerja dari alat gerak kapal (propulsor) untuk mendorong badan kapal $\mathrm{P}=\mathrm{T} \times \mathrm{Va}$. Daya yang disalurkan ( PD ) adalah daya yang diserap oleh baling-baling kapal guna menghasilkan daya dorong sebesar PT

$$
\mathrm{P}=2 \quad \text { Qdn }
$$

Dimana : Q adalah torsi yang disalurkan dari main engine dan $\mathrm{n}$ adalah jumlah propeller.

Daya poros ( PS ) adalah daya yang terukur hingga daerah didepan bantalan tabung poros baling-baling ( sterntube ) dari sistem perporosan penggerak kapal. Efisiensi Shaft sekitar $98 \%$ dari Daya Rem atau Brake Power.

\section{Hasi dan Pembahasan}

Tabung poros baling-baling adalah suatu pipa yang mempunyai ketebalan tertentu , didalamnya terdapat poros baling-baling yang berputar mendorong kapal. Untuk pengikatannya, bagian ujung depan tabung poros diikat dengan sekat tabung buritan dan bagian ujung belakang diikat atau ditumpu oleh bos poros baling-baling dengantujuan untuk menahan gayayang sangat besar dari bekerjanya sistim penggerak kapal.

\subsection{Poros Baling-baling Dengan Pelumasan Air Laut}

Apabila suatu poros baling-baling didalam gerakan putarnya terhadap bantalan tidak diperlukan sistem kedap poros di bagian 
belakangnya, maka dapat dipastikan bahwa media pelumasan untuk sistem ini adalah dengan menggunakan air laut. Secara umum hubungan antara poros baling-baling dengan bantalan belakang dan bantalan depan dapat dilihat pada gambar 1

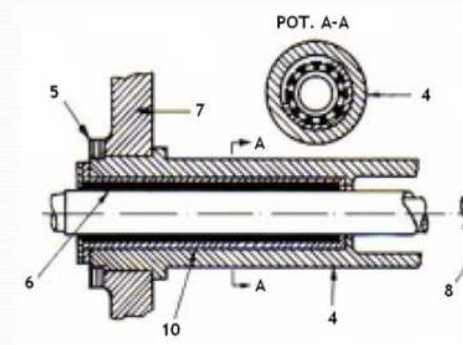

Gambar 1. Sistem poros pelumasan air laut.

$\begin{array}{ll}\text { 1. } & \text { Sekat Ceruk Buritan } \\ \text { 2. } & \text { Penekan paking } \\ \text { 3. } & \text { Paking } \\ \text { 4. } & \text { Stern Tube } \\ \text { 5. } & \text { Baut Stern Tube } \\ \text { 6. } & \text { Bantalan poros } \\ \text { 7. } & \text { Linggi buritan } \\ \text { 8. } & \text { Poros Baling-baling } \\ \text { 9. } & \text { Baut pengikat } \\ \text { 10. } & \text { Rumah bantalan }\end{array}$

Sistem Pelumasan air laut

- Air laut masuk melalui celah celah bantalan bagian belakang

- Pada bagian depan digunakan remes paking untuk menjaga kekedapan

- Menggunakan bantalan kayu pok ( lignum vitae) atau bahan karet sintetis

Proses pelumasan : air laut masuk kedalam tabung buritan melalui celah, celah ini didapat antara poros baling-baling dan bantalan belakang. Sedang pada bagian ujung depan tabung ini dipasang seal, paking dan penekan paking untuk mencegah masuknya air laut kedalam kamar mesin. Penekan paking ini digunakan untuk menekan paking jika terjadi perembesan atau kebocoran air pelumas dengan cara memutarlbautpenekan. Pada sistem ini , bahan bantalan dapat berupa Pok Hout atau kayu Pok,cuttles bearing atau karet ataupun karet sintetis. Pada bahanbahan tersebut dibuat alur agar air laut dapat mengalir secara teratur membasahi permukaan bantalan yang bergesekan dengan poros, air laut disini berfungsi sebagai pelumas. Tanpa adanya air laut ini, bantalan akan kering dan panas sehingga terbakar yang berakibat perputaran poros terhadap bantalan akan macet. Pada bantalan dibagian depan secara khusus dibuatkan suatu sistem Kekedapan agar air laut tidak langsung masuk kedalam kamar mesin, meskipun disini tidak secara total air laut berhenti, dan masih ada sedikit yang harus menetes kedalam kamar mesin. Untuk menyetop tetesan air laut ini dapat dilakukan dengan mengatur mur baut penekan dikencangkan atau dikendorkan. Gambar dari bahan bantalan dengan sistem pelumasan air laut, sistem kekedapan bantalan depan dapat dilihat pada gambar 2 .
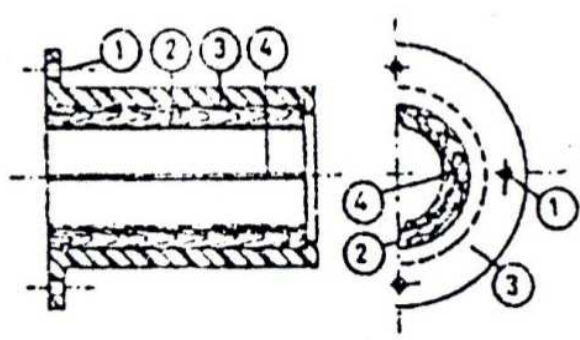

Gambar 2. Bantalan Belakang

1) Lubang baut pengikat rumah bantalan

2) Bantalan belakang (pok hout)

3) Rumah bantalan belakang (bronze)

4) Alur pelumas air laut

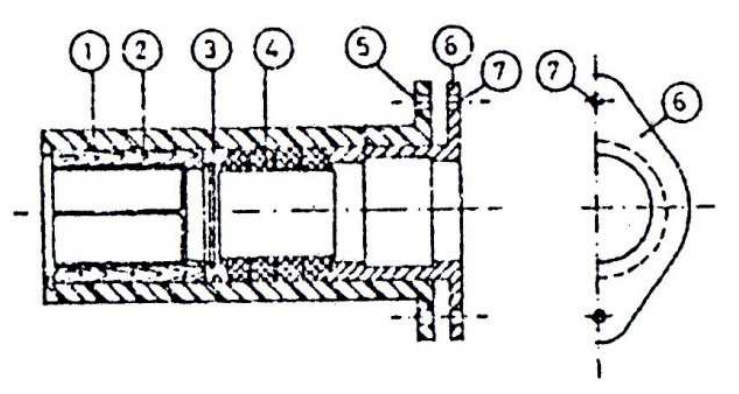

Gambar 3. Bantalan Depan 
1) Rumah bantalan depan (bronze)

2) Bantalan depan (pok hout)

3) Ring penahan reamees paking (bronze)

4) Rames paking

5) Lubang baut pengikat rumah bantalan

6) Penekan remes paking (bronze)

7) Lubang baut penekan remes paking

Panjang bantalan belakang minimal $4 \mathrm{x}$ dari diameter poros, dan panjang bantalan depan minimal 1.5 kali dari diameter poros. Mengenai material dari poros baling-baling sangat penting untuk direncanakan dan ditetapkan secara tepat, hal ini mengingat bahwa pelumasan dilakukan dengan air laut yang bersifat korosif, yang berarti bahan poros harus tahan terhadap korosi yang dapat merusak poros. Selain harus diikuti persyaratan dari Biro Klasifikasi yang telah menetapkan misalnya bahwa kuat tarik minimum baja untuk poros antara 42 - 72 $\mathrm{kg} / \mathrm{cm} 2$, dan untuk mendapatkan pengakuan dari Biro Klasifikasi bahan poros harus menjalani uji material sehingga dapat dipastikan bahwa kekuatan poros terjamin. Perlu diketahui bahwa beban yang harus dipikul oleh poros secara pasti ada tiga ( 3 ) macam yaitu gaya tarik, gaya tekan dan gaya puntir. Pada saat kapal bergerak maju, maka akibat adanya gaya dorong baling-baling terhadap air yang diteruskan ke pondasi mesin dan mendorong kapal maju kedepan , poros akan mengalami gaya tekan , sedangkan adanya putaran mesin yang memutar poros maka poros akan mengalami gaya puntir. Beberapa cara atau usaha untuk memperpanjang umur poros karena resiko korosi ataupun faktor gesekan dengan bantalan, dapat dilihat pada gambar 1 .

Disini pada posisi kedudukan bantalan depan dan belakang dipasang semacam selubung atau pelindung atau sleeve, biasanya terbuat dari bahan bronze yang dipasang dengan cara press fit, fungsi sleeve ini adalah apabila digunakan bahan poros yang kurang tahan terhadap korosi maka sleeve berfungsi melindungi dari korosi, dan yang sangat penting apabila ada keausan karena adanya gesekan dengan bantalan maka hanya sleeve saja yang aus, sehingga bila sudah cukup parah keausannya maka hanya sleeve saja yang diganti karena lebih murah dibanding harus mengganti poros yang harganya jauh lebih mahal.

Ketebalan daripada sleeve ini menurut peraturan dari Biro Klasifikasi Indonesia menetapkan bahwa ketebalan sleeve tidak boleh kurang dari :

$$
S=0,03 d+7,5 \mathrm{~mm}
$$

Keterangan : $\mathrm{d}=$ diameter poros balingbaling.

Pada posisi ditengah antara bantalan depan dan bantalan belakang terdapat lapisan selubung atau pelindung juga yang disebut rubber sleeve atau lapisan karet, disini hanya berfungsi sebagai pelindung terhadap korosi akibat pelumasan air laut saja, pada keadaan lain juga dapat dibuat dari bahan fibre glass yang untuk finishing harus dibubut dibangku bubut agar lebih halus, supaya tidak timbul getaran ataupun friction yang terlalu besar karena lapisan karet atau fibre yang kasar.

Dapat ditambahkan disini bahwa untuk bronze sleeve sebelum dipasangkan pada poros , maka harus dilakukan uji tekan hidrostatik sebesar $2 \mathrm{~kg} / \mathrm{cm} 2$ ( menurut Biro Klasifikasi Indonesia ), hal ini dimaksudkan agar kwalitas bahan sleeve dapat terkontrol dengan baik.

\subsection{Poros Baling baling Dengan Pelumasan Minyak}

Didepan telah dibahas mengenai poros baling-baling yang menggunakan pelumasan air laut dan tidak menggunakan sistem kedap pada bagian belakang. Berikut ini kita lihat poros baling-baling didalam gerak putarannya terhadap bantalan menggunakan minyak atau olie sebagai bahan pelumasnya, dimana sistemnya menjadi lain bila dibandingkan dengan yang pertama. Baik 
ditinjau dari bahan poros, bahan bantalan maupun keharusan pemasangan sistem kedap pada sistem ini. Secara umum hubungan antara poros baling-baling, bantalan poros, minyak pelumas dan sistem kekedapan dapat dilihat pada gambar 3

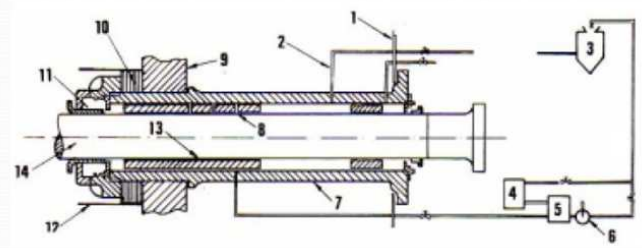

\section{Gambar 4. Poros Baling-baling Dengan} Sistim Kedap

1) Sekat ceruk buritan

2) Sistem pipa pelumas

3) Tangki minyak pelumas

4) Pompa

5) Saringan minyak pelumas

6) Pompa tangan

7) Tabung

8) Alur minyak pelumas

9) Linggi buritan

10) Baut Stern Tube

11) Paking

12) Plat pelindung

13) Bantalan

14) Poros baling-baling

Sistem pelumasan minyak

- Pelumasan menggunakan minyak pelumas

- Bantalan menggunakan babiet metal

- Minyak pelumas ditampung dalam tangki dan dialirkan ke tabung buritan

- Sistem kekedapan menggunakan seal baik di depan maupun di belakang

- Dilengkapi dengan pompa untuk sirkulasi minyak lumas

Proses pelumasan : bantalan mempunyai celah-celah atau lubang-lubang dengan ukuran tertentu , agar minyak pelumas dapat merata melumasi permukaan poros dan bantalan . Minyak pelumas ditampung dalam tangkikhusus yang dihubungkan dengan sistem pipa ke tabung buritan atau tabung poros baling-baling. Dengan pemompaan minyak pelumas dapat bersirkulasi dan melumasi bagian-bagian yang memerlukannya.Untuk mencegah air laut supaya tidak masuk ke sistem pelumasan ialah dengan paking-paking dan seal. Untuk melindungi paking pada ujung bos poros baling-baling dipasang plat pelindung yang berfungsi untuk mencegah masuknya bendabenda yang dapat mengakibatkan terjadinya kerusakan paking.

Pada sistim ini bahan bantalan yang lazim digunakan antara lain berupababit metal, ferrobestos, atau jenis lain yang sesuai untuk pelumasan dengan minyak. Pada bahan bantalan yang berupa babit metal ataupun bahan yang lain, terdapat alur-alur untuk lewat minyak lumas baik untuk bantalan belakang maupun bantalan depan. Untuk mencegah bocornya minyak pelumas ke air laut atau sebaliknya mencegah masuknya air laut ke dalam tabung poros (stern tube) yang dapat mengakibatkan rusaknya minyak pelumas , maka pada sela-sela antara balingbaling dan kocker ( stern bush) dipasang peralatan sistem kedap poros yang biasa disebut cederval, sedangkan untuk mencegah jangan sampai minyak pelumas mengalir ke bagian seal kedap. Seal kedap ini fungsinya tidak seberat cederval, karena hanya sebagai pencegah minyak pelumas mengalir kekamar mesin.

Berbagai macam cederval yang sering dijumpai digunakan antara lain yang menggunakan ring karet, menggunakan pegas ,simplex dan seal karet, yang berfungsi sebagai part elastis agar memiliki daya lentur atau elastis dan sekaligus mencegah penetrasi air laut ke bagian poros pada cederval. Kegunaan daya lentur atau elastis diperlukan untuk agar bagian depan rear cederval yang dilapisi babit dengan daya tekan tertentu akibat elastisnya karet atau seal, dapat menempel dengan baik terhadap permukaan bronze yang disekrup diam dengan stern bush. 
Macam-macam Tipe Cederval

Untuk jelasnya beberapa macam tipe cederval dapat dilihat pada gambar 4. :

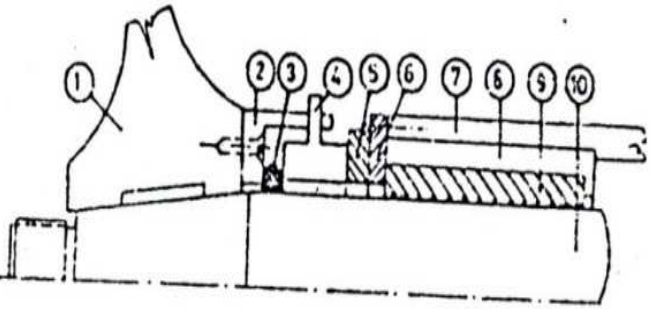

Gambar 5.a. Cederval Dengan Ring Karet

Keterangan :

1) Propeller

2) Rumah Ring Karet

3) Ring Karet

4) Cederval

5) Babit Pada Cederval

6) Ring Bronze

7) Koker Belakang

8) Rumah Bantalan

9) Bantalan Belakang

10) Poros Propeller

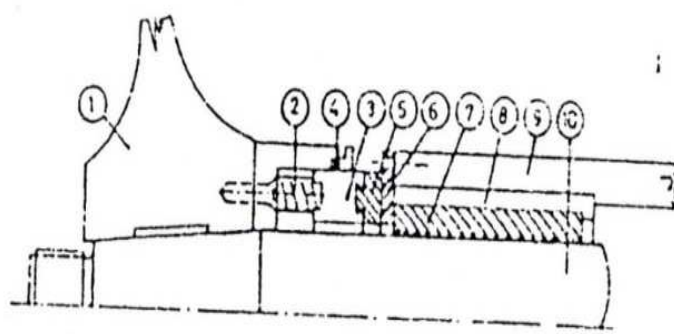

Gambar 5.b. Cederval Dengan Sistim Pegas

Keterangan :

1) Propeller

2) Pegas.

3) Rumah Pegas dan Cederval

4) Seal / Ring Karet

5) Babit Pada Cederval

6) Ring Bronze

7) Bantalan Belakang

8) Rumah Bantalan

9) Koker Belakang

10) Poros Propeller

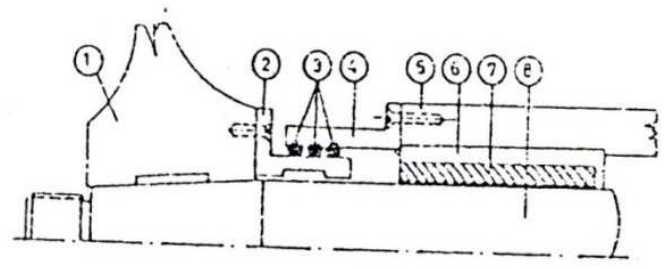

Gambar 5.c. Cederval Dengan Sistim Simplex

Keterangan :

1) Propeller

2) Pelindung Poros Propeller

3) Seal 4. Rumah Seal

4) Koker Belakang

5) Rumah Bantalan Belakang

6) Bantalan Belakang

7) Poros Propeller

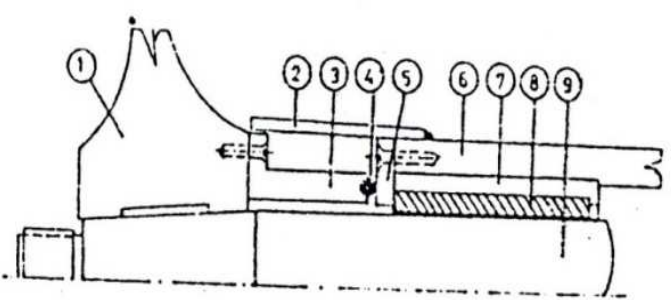

Gambar 5.d. Cederval Dengan Seal

Keterangan :

1) Propeller

2) Plat Pelindung

3) Rumah Seal

4) Seal

5) Ring Bronze

6) Koker Belakang

7) Rumah Bantalan Belakang

8) 8.Bantalan Belakang

9) Poros Propeller

Panjang bantalan dengan pelumasan minyak ini berbeda dengan pelumasan air laut, untuk bantalanbelakang $2 \mathrm{x}$ diameter poros dan untuk bantalan depan $0,8 \times$ diameter poros, sedangkan jarak antara bantalan dapat dihitung dengan rumus : 


$$
\text { L maks. = K1 x d }
$$

\section{Keterangan}

$\mathrm{d}=$ diameter poros baling-baling ( $\mathrm{mm}$ )

$\mathrm{K} 1=450$ untuk bantalan timah putih (babit) 280 - 350 untuk pelumasan air dengan bantalan pok hout.

Bila putaran poros lebih besar dari $350 \mathrm{rpm}$, maka jarak bantalan maksimum dihitung dengan rumus :

$$
\text { L maks. }=\mathrm{K} 2 . \mathrm{d} / \mathrm{n}
$$

$\mathrm{d}=$ diameter poros baling-baling $(\mathrm{mm})$

$\mathrm{n}=$ rpm poros baling-baling

$\mathrm{K} 2=8400$ untuk bantalan babit dengan pelumasan minyak.

Perlu diketahui bahwa sebagai tabung poros baling-baling digunakan dari bahan baja dengan tebal minimum $15 \mathrm{~mm}$ dan mampu mengatasi test tekan sebesar $2 \mathrm{~kg} / \mathrm{cm}$.

Untuk sistim pelumasan dengan minyak,.karena didalam sistim ini tidak ada air laut didalam tabung ( stern tube) maka tidak perlu dikawatirkan adanya korosi, sehingga faktor yang perlu dipikirkan hanya resiko keausan karena bergesekan dengan bantalan yang dapat diatasi dengan pemasangan sleeve, tapi juga sering dijumpai bahwa poros tidak dilengkapi dengan sleeve, namun untuk memudahkan saat penghalusan diatas mesin bubut maka diameter bantalan pada posisi bantalan dibuat bertingkat terhadap diameter poros diantara dua bantalan muka dan belakang. Bahan poros dapat dari stainless steel, forget steel ataupun malibdenum steel dengan catatan bahwa kekuatan tarik sesuai dengan persyaratan Biro Klasifikasi Indonesia yaitu antara 42 $72 \mathrm{~kg} / \mathrm{cm} 2$.

\subsection{Kekurangan dan kelebihan}

Sebenarnya tidak ada masalah yang dominan didalam menetapkan apakah suatu kapal harus menggunakan pelumasan poros dengan minyak dan dengan dilengkapi cederval ataukah dengan menggunakan air laut sebagai media pelumasnya, dikarenakan masing-masing sistem memiliki kekurangan dan kelebihan masing-masing. Untuk itu kita lihat bagaimana sifat-sifat atau karakteristik dari kedua sistem tersebut sehingga dapat terlihat dengan jelas masing performanya.

Adapun kekurangan dan kelebihan pada pelumasan air laut sebagai berikut :

Kekurangan :

1) Pelaksanaan bubut pok hout memperhitungkan kembang susut dari pok hout basah atau kering

2) Secara relative tingkat keausan bantalan lebih tinggi

3) Rawan terhadap resiko kemasukan kotoran atau pasir masuk disela-sela poros dan bantalan

4) Adanya air laut yang masuk ke kamar mesin

Kelebihan :

1) Konstruksi sederhana

2) Tingkat ketelitian lebih mudah

3) Beaya pembuatan dan perawatan bantalan lebih murah

4) Bahan pok hout mudah di dapat

5) Pada jenis segmen kerusakan dapat diganti sebagian

Jika dengan pelumasan minyak adalah sebagai berikut :

Kekurangan :

1) Konstruksi cederval dan babit sulit

2) Memerlukan ketelitian yang tinggi

3) Beaya pembuatan dan perawatan tinggi

4) Cukup rawan terhadap benda-benda keras dibawah air

5) Perbaikan tidak dapat dilakukan di sembarang tempat

6) Rawan resiko kebocoran air laut bercampur dengan minyak lumas.

Kelebihan :

1) Poros dan bantalan selalu bersih bebas dari kotoran pasir dari laut

2) Sistim poros cukup terlindung dari resiko korosi

3) Tidak ada air laut yang mengalir ke kamar mesin

4) Tingkat keausan relatip lebih rendah 


\section{Kesimpulan}

Untuk sistem pelumasan poros dengan air laut seal dan paking kekedapan poros hanya dipasang pada ujung depan stern tube saja, sehingga air laut dapat masuk kedalam tabung poros tetapi tidak dapat masuk kedalam kamar mesin. Sedangkan untuk pelumasan poros dengan minyak pelumas seal dan paking kekedapan poros dipasang di ujung belakang dan ujung depan poros baling-baling, yang berfungsi sebagai pengedap poros sehingga mampu menahan keluarnya minyak pelumas atau mencegah masuknya air laut kedalam tabung poros baling-baling.

\section{Daftar Pustaka}

- A. Bayne Neild JR .1965."Modern Marine Enginers Manual" CambridgeMaryland.

- G. Galver. 1967. Technology Of Ship Repairing, Mir Publisher, Moscow.
- Harval, 1978, Ressistance and Propulsion of Ship, Jhon Wiley and Sous, New York.

- Lloyd Woollard, M.A, 1956. M.I.N.A, "Naval Architects Shipbuilders pocket Book London.

- Ridwan,Moh. 2009. Perpaduan Antara Propeller dan Daun Kemudi Guna Mengoptimalkan Propulsi dan Manuver Kapal serta Efisiensi Bahan Bakar, D-III Teknik Perkapalan, UNDIP: Semarang.

- Saragih,Rapelman . 2011. Pengaruh jumlah dan posisi rudder terhadap kemampuan manoevering kapal, Department of Marine Engineering, ITS : Surabaya.

- Sukarsono, 1995, Sistim dan Perlengkapan Kapal, PT Pamator Pressindo Jakarta.

- Wiranto Arismunandar 1988. Motor Bakar Torak. 